\title{
Primary common bile duct closure after open exploration for choledocholithiasis
}

\author{
Magdy A Sorour, MD
}

\begin{abstract}
GIT Surgery Unit, General Surgery Department, University of Alexandria, Egypt.
\end{abstract}
Background: Choledocholithiasis is the second-most common complication of cholecystolithiasis, occurring in approximately 10-15\% of patients. For choledocholithiasis, there are two methods for CBD exploration to extract stones: either endoscopically, by endoscopic retrograde cholangiopancreatography (ERCP) with or without sphincterotomy, or surgically, by an open or laparoscopic method. Open CBD exploration has been the principal treatment in many hospitals and is still considered the gold standard for the removal of CBD stones. Following common bile duct (CBD) exploration and stone removal, the choice for closure of the incised bile duct lies between primary closure and T-tube drainage. There are many papers reported by different authors, which support the direct closure of the duct immediately after exploration. The aim of this study was to assess the clinical short-term results and benefits of primary closure of the common bile duct after open choledochotomy for CBD calculi in a developing country like Egypt.

Methods: Between December 2010 and December 2013; 74 patients with a radiological evidence of common bile duct stones were admitted and treated at the Gastrointestinal Surgery Unit, Main Alexandria University Hospital in whom the common bile duct diameter was equal to or larger than $8 \mathrm{~mm}$. Those associated with distal CBD strictures, multiple intrahepatic calculi, or malignancy were excluded. After approval of local ethics committees, all patients included in this study were informed well about the operative procedure and an informed written consent was obtained from every patient before carrying the procedure. All patients' data, surgical procedures, complications and follow-up details were collected and analyzed.

Results: CBD exploration and stone removal followed by primary closure was performed in all patients. The mean age of patients was $55.3 \pm 15.7$ years (range, 37-75 years). Most of the patients presented with biliary colic (74\%). Sixty-seven patients (90\%) had concomitant gallstones as evident by preoperative abdominal ultrasound. The mean diameter of CBD was $12.3 \pm 3.2 \mathrm{~mm}$ (range, $8-27 \mathrm{~mm}$ ). The maximum number of stones was 14. The total complication rate was 5.4\% (4/74) and included wound infection with delayed wound healing and bile leakage. One patient had a bile leakage that subsided on the third postoperative day. There was no postoperative biliary obstruction, residual stones, cholangitis, pancreatitis, biliary peritonitis or intra-abdominal collections. The mean postoperative hospital stay was $4.2 \pm 1$ days. There was no perioperative mortality. The mean duration of follow-up was $10.8 \pm 3.2$ months (range, 4-18 months). There was no recurrence of CBD stones or stricture of bile ducts observed during the follow up period and postoperative ultrasound findings were normal.

Conclusion: Primary closure of the CBD after open choledochotomy for choledocholithiasis is safe, feasible and effective with shorter hospital stays and lower costs.

Key words: Choledocholithiasis; cholelithiasis; open choledochotomy; common bile duct exploration; primary closure.

\section{Introduction:}

Choledocholithiasis is the second-most common complication of cholecystolithiasis, occurring in approximately $10-15 \%$ of 
patients. ${ }^{1-5}$ The literature suggests that at least $3-10 \%$ of patients undergoing cholecystectomy will have CBD stones. ${ }^{5}$ Choledocholithiasis may lead to further complications, including biliary colic, obstructive jaundice, cholangitis, and pancreatitis. ${ }^{3,4,6}$

For choledocholithiasis, there are two methods for CBD exploration to extract stones: either endoscopically, by endoscopic retrograde cholangiopancreatography (ERCP) with or without sphincterotomy, or surgically, by an open or laparoscopic method. ${ }^{7}$

In the modern 'minimally invasive approach' era, the current standard protocol for the treatment of CBD stones is to clear and drain the CBD by ERCP, followed by laparoscopic cholecystectomy. However; ERCP is less successful than open surgery in CBD stone clearance and is associated with a higher morbidity and mortality. ${ }^{8}$ If the patient has many and/or large stones, it can take considerable time for duct clearance, and this is associated with high costs. ${ }^{9}$ There is also an increased recurrence rate of CBD stones following endoscopic removal. ${ }^{10}$

Laparoscopiccommonbileductexploration (LCBDE) for treating choledocholithiasis is well known these days, ${ }^{9}$ but remains controversial. This procedure demands skills and equipment, and is therefore used by few surgeons. ${ }^{11}$ Moreover, the superiority of this procedure for complete CBD stone clearance has not yet been proven, which limits its applicability, despite its short hospital admission. ${ }^{12-15}$

Despite these advancements, many surgeons, especially in the developing world, still perform open cholecystectomy with common bile duct (CBD) exploration for choledocholithiasis due to lack of training as well as equipment. ${ }^{16-18}$ Even in the developed world, there are places where these resources may not be available. In fact, a recent survey from the rural areas of United States of America showed that surgeons had to resort to open biliary surgical procedures, due to lack of equipment. ${ }^{19}$.

Open CBD exploration has been the principal treatment in many hospitals and is still considered the gold standard for the removal of CBD stones. ${ }^{6}$ Following common bile duct (CBD) exploration and stone removal, the choice for closure of the incised bile duct lies between primary closure and T-tube drainage.1,7,20,21 Choledochotomy followed by T-tube drainage is a traditional surgical treatment for chloledocholithiasis for most of this century. ${ }^{22,23}$. Although it is true that the T-tube has been used and has proven to be a safe and effective method for postoperative biliary decompression, it is not without complications, which are present in up to $10 \%$ of patients. ${ }^{1,20}$ Some of these complications are serious, such as bile leak, tract infection or acute renal failure from dehydration, particularly in elderly patients. The most frequent of these is bile leakage resulting from T-tube displacement or early removal without adequate tract formation, which is reported to occur in $1-19 \%$ of cases.1,11,23-25 In addition, having bile drainage in place for weeks causes significant discomfort in patients and delays their return to work. $20,21,26-28$

Primary closure of the CBD after exploration is not new. There are many papers reported by different authors, which support the direct closure of the duct immediately after exploration. 8,16,23,27,29-34 With the help of a choledochoscope during surgery, direct visualisation of the CBD is possible and retained stones are not a problem.

The aim of this study was to assess the clinical short-term results and benefits of primary closure of the common bile duct after open choledochotomy for CBD calculi in a developing country like Egypt.

\section{Methods:}

Between December 2010 and December 2013; 74 patients with a radiologically confirmed diagnosis of common bile duct stones were admitted and treated at the Gastrointestinal Surgery Unit, Main Alexandria University Hospital. Only patients with CBD diameter equal to or larger than $8 \mathrm{~mm}$ were included; those with associated distal CBD strictures, multiple intrahepatic 
calculi, severe pancreatitis, suppurative cholangitis or malignancy were excluded. After approval of local ethics committees of both the General Surgery Department and the Alexandria Faculty of Medicine, all patients included in the study were informed well about the operative procedure and an informed written consent was obtained from every patient before carrying the procedure.

All patients were subjected to complete history taking, thorough clinical examination, routine laboratory studies, liver function tests, liver enzymes, and abdominal ultrasonography. Whenever indicated; MRI with magnetic resonance cholangiopancreatography

(MRCP)

Figure (1), or multi-slice CT (MSCT) abdomen was performed.

All patients were operated upon under general anesthesia. Prophylactic intra-venous antibiotic (a third generation cephalosporin and metronidazole) was given to all patients at the time of induction of anesthesia and was continued postoperatively for at least two days. Prophylactic low molecular weight heparin was given to all obese patients and those at high risk and was continued postoperatively during the period of hospital stay.

A right subcostal incision was used to provide exposure of the CBD. The first step was cholecystectomy, unless the gall bladder had already been removed, followed by common bile duct exploration through a supraduodenal vertical incision between stay sutures Figure (2). Stones were taken out, followed by generous saline irrigation in the usual manner to ensure patency. A 5-8 Fr infant feeding tube was used for irrigation to allow stones to float up alongside to be extruded at the choledochotomy. Passage of the tube through the ampulla (if no obstruction was present) was signaled by free flow of irrigant to the duodenum with no return through the choledochotomy. In most cases the $\mathrm{CBD}$ was cleared using this technique. If however, a stone at the distal end could not be disimpacted, a transduodenal sphincteroplasty was done and patients were excluded from the study. Adequate clearance of the duct was confirmed with a choledochoscope. Then primary closure of the CBD was performed using interrupted absorbable sutures (Vicryl $4 / 0$, Ethicon). Suture closure was carried out delicately to avoid tearing the duct wall. Transcystic intraoperative completion cholangiogram was routinely performed to rule out the possibility of retained stones or distal stricture. The diameter of the CBD was measured on cholangiography during the operations. Having excluded from the study, some patients were treated by choledochoenterostomy when their intraoperative cholangiogram showed distal stricture Figure (3). At the end of the procedure, an 18-20 Fr drain was placed in the sub-hepatic space and was kept in situ in all patients for two days postoperatively. Patients were discharged after laboratory findings were normal and no drains were required.

All patients' data, operative findings, hospital stay, postoperative morbidity and follow up details were recorded and analyzed.

Biliary leakage was defined as any yellow bile-like fluid coming out of the sub hepatic drain or after the removal of the drain, aspiration of yellow coloured bile-like fluid under ultrasound guidance from sub hepatic peritoneal space $(300 \mathrm{~mL})$.

Data were presented with numbers, percentage, arithmetic mean (X) and standard deviation (SD) and were analyzed with SPSS (version 16) statistical software. P values less than 0.05 were considered to be statistically significant.

\section{Results:}

From December 2010 through December 2013, 74 patients (26 males and 48 females) with a radiologically confirmed CBD stones were operated upon in the Gastrointestinal Surgery Unit, Main Alexandria University Hospital.

All 74 patients were diagnosed with preoperative ultrasound. Magnetic resonance cholangiopancreatography (MRCP) and Computed tomography (CT) scans were performed preoperatively in 17 and 5 cases, respectively. 
Twelve patients had previously undergone cholecystectomy (open in eight and laparoscopic in four patients). Seven patients underwent other gastrointestinal tract surgeries.

Seventeen patients refused to undergo preoperative ERCP for stone retrieval for fear of its complications. Twelve patients underwent preoperative ERCP that failed to extract stones. Two patients were not candidate for ERCP due to alteration of the GIT from previous surgery. The remaining 43 patients with multiple and large stones underwent surgery without preoperative ERCP as it was expected to fail.

The mean age of patients was 55.3 \pm 15.7 years (range, 37-75 years). Patients' demographic data, preoperative parameters and clinical presentation are listed in Table (1). Most of the patients presented with biliary colic (74\%). Other clinical presentations were obstructive jaundice, acute cholecystitis, and cholangitis. All patients with cholangitis were stabilized by antibiotic therapy before the operation. Out of 74 patients, 15 patients had co-morbidities like diabetes mellitus and hypertension.

Eighty-eight percent of surgeries (65 patients) were done on elective basis and $12 \%$ (9 patients) on an emergency basis. Sixty-seven patients (90\%) had concomitant gallstones as evident by preoperative abdominal ultrasound. CBD exploration and stone removal followed by primary closure was performed in all patients. Preoperative abdominal ultrasound showed the size of CBD and number of CBD stones, which was then confirmed during the operation. The mean diameter of CBD was $12.3 \pm 3.2 \mathrm{~mm}$ (range, $8-27 \mathrm{~mm}$ ). The maximum number of stones was 14 . None of the patients had residual stones on intraoperative cholangiography Table (2).

Seventy patients did not suffer any complication. The total complication rate was $5.4 \%$ (4/74) and included wound infection with delayed wound healing and bile leakage. All wound infections were successfully treated by appropriate antibiotics with removal of few stitches for proper drainage and daily dressings. One patient had a bile leakage that subsided on the third postoperative day. There was no postoperative biliary obstruction, residual stones, cholangitis, pancreatitis, biliary peritonitis or intra-abdominal collections. The mean postoperative hospital stay was $4.2 \pm 1$ days (range, 3-7 days). There was no perioperative mortality.

The mean duration of follow-up was 10.8 \pm 3.2 months (median, 12months; range, 4-18 months). There was no recurrence of CBD stones or stricture of bile ducts observed during the follow up period and postoperative ultrasound findings were normal.

\section{Discussion:}

Symptomatic gallstone disease is a very common indication for abdominal surgery. ${ }^{35}$ Before the laparoscopic era, cholecystectomy and CBD stones were removed in a single procedure. This approach has been effective with morbidity below $15 \%$ and mortality below $1 \%$ in a patient up to 65 years old. ${ }^{36}$ In the era of minimally invasive procedures, open laparotomy for CBD exploration may still be the choice in some hospitals in developing countries.

In this study, all patients underwent primary closure of the CBD after open choledochotomy for choledocholithiasis. Choledochoscopy and intraoperative cholangiography were performed to ensure complete duct clearance.

Patients with CBD diameter less than 8 $\mathrm{mm}$ were not treated by primary closure of the CBD and were excluded from the study for fear of CBD stenosis and later stricture. Such patients were treated in Alexandria Gastrointestinal Surgery Unit by either; (1) preoperative ERCP and endoscopic sphincterotomy followed by cholecystectomy, (2) laparoscopic cholecystectomy and laparoscopic CBD exploration, ${ }^{37}$ (3) combined laparoscopic cholecystectomy and intraoperative ERCP and endoscopic sphincterotomy (LC + IO-ERCP + ES). ${ }^{38}$ Those associated with distal stricture were also excluded and were treated by preoperative ERCP and endoscopic sphincterotomy; 

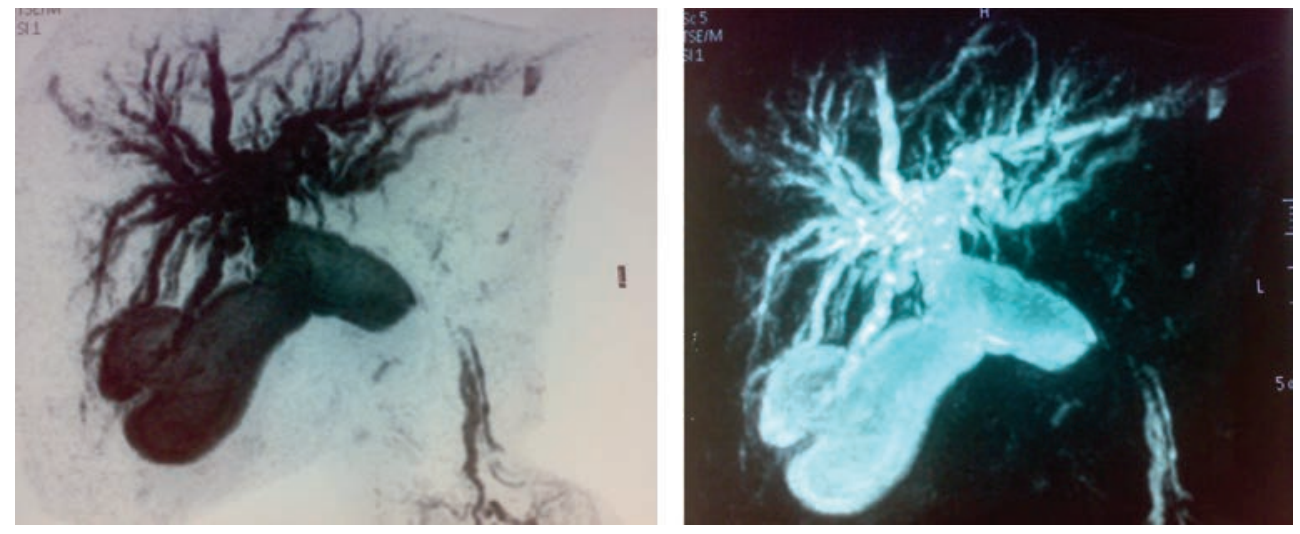

Figure (1): MRCP showing marked dilatation of the CBD and intrahepatic biliary radicals with abrupt arrest at the mid-CBD showing positive meniscus sign, in favor of a large CBD stone.
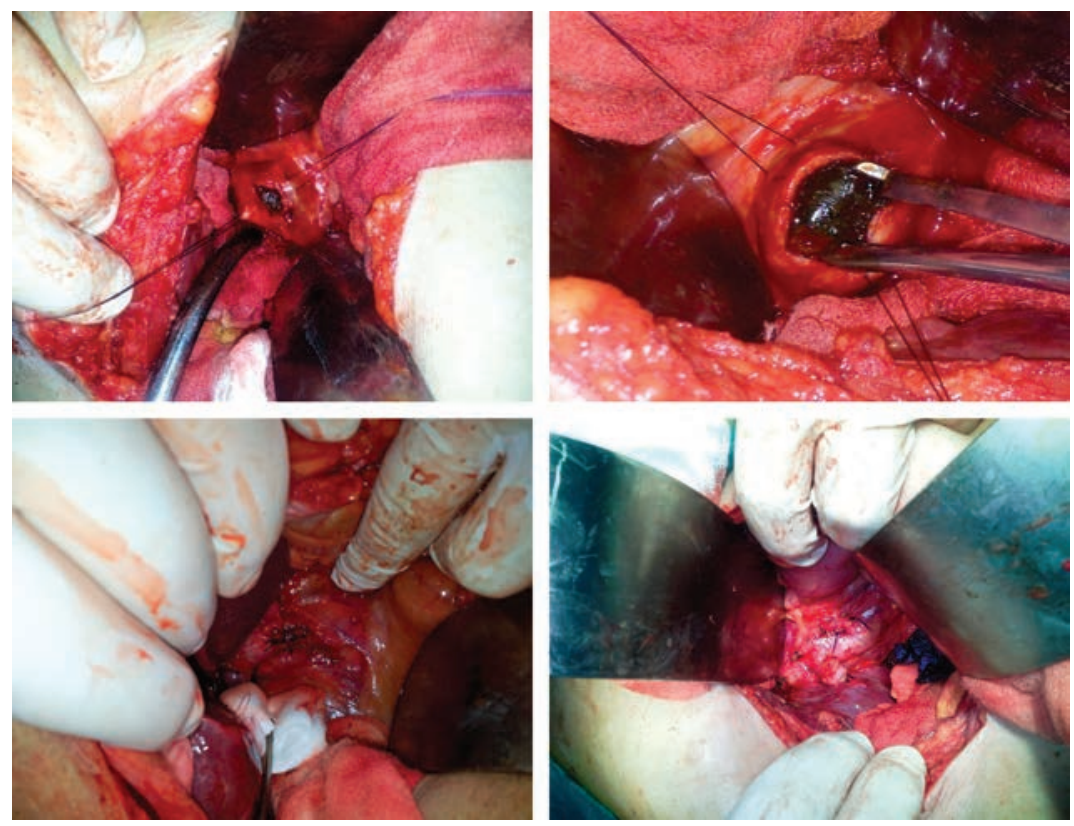

Figure (2): Open choledochotomy for CBD stone extraction followed by primary closure.
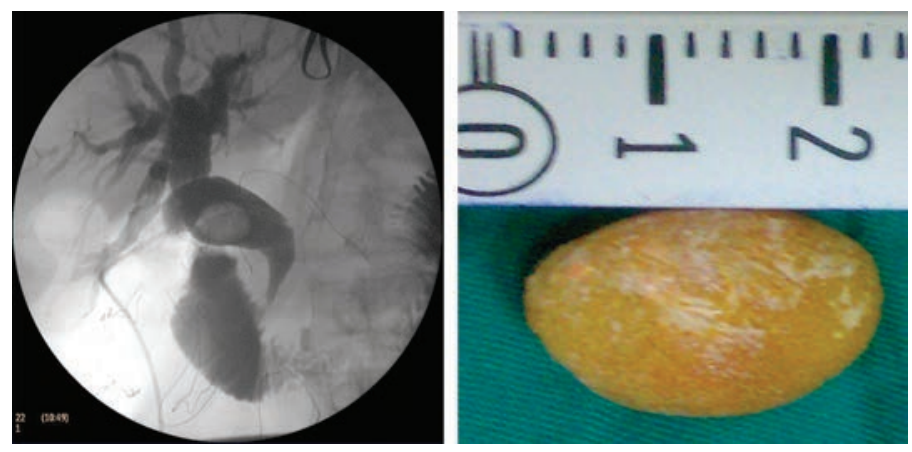

Figure (3): Intraoperative cholangiogram showing marked dilatation of the CBDand intrahepatic biliary radicals, with smooth tapering distal CBD stricture, and a large CBD stone with free passage of the dye into the duodenum. This patient underwent choledochoduodenostomy and excluded from the study. 
Table 1: Patients' demographic data and preoperative parameters.

\begin{tabular}{|c|c|c|c|}
\hline Patients' data & Number $=74$ & Median & Range \\
\hline Age (in years) & $55.3 \pm 15.7$ & 58.4 & $37-75$ \\
\hline Gender & & & \\
\hline Male & $26(35 \%)$ & & \\
\hline Female & $48(65 \%)$ & & \\
\hline BMI (body mass index) & $29 \pm 8.7$ & 36 & 19.2 \\
\hline Previous abdominal surgery & & & -46.4 \\
\hline Open cholecystectomy & $8(10.8 \%)$ & & \\
\hline Laparoscopic cholecystectomy & $4(5.4 \%)$ & & \\
\hline Gastrojejunostomy for benign & $2(2.7 \%)$ & & \\
\hline gastric outlet obstruction & & & \\
\hline Splenectomy for blood disease & $2(2.7 \%)$ & & \\
\hline Perforated peptic ulcer & $1(1.4 \%)$ & & \\
\hline Hernioplasty for ventral hernia & $1(1.4 \%)$ & & \\
\hline $\begin{array}{l}\text { Pancreatic necrosectomy for } \\
\text { acute pancreatitis }\end{array}$ & $1(1.4 \%)$ & & \\
\hline Presentation & & & \\
\hline Biliary colic & $55(74.3 \%)$ & & \\
\hline Obstructive jaundice & $31(41.9 \%)$ & & \\
\hline Recurrent fever & $23(31.1 \%)$ & & \\
\hline Acute cholecystitis & $10(13.5 \%)$ & & \\
\hline Cholangitis & $7(9.5 \%)$ & & \\
\hline Acute pancreatitis & $2(2.7 \%)$ & & \\
\hline Associated co-morbidities & $15(20.3 \%)$ & & \\
\hline Hypertension & $8(10.8 \%)$ & & \\
\hline Diabetes Mellitus & $5(6.8 \%)$ & & \\
\hline Liver cirrhosis & $2(2.7 \%)$ & & \\
\hline Concomitant gallbladder stones & $67(90.5 \%)$ & & \\
\hline Preoperative liver functions & & & \\
\hline Total serum bilirubin (mg/dL) & $2.7 \pm 2.1$ & 2.4 & $0.3-9.7$ \\
\hline Serum ALT (U/L) & $92.4 \pm 42.7$ & 66 & $37-331$ \\
\hline Serum alkaline phosphatase & $469.3 \pm 223.7$ & 561 & $94-871$ \\
\hline Preoperative ERCP & & & \\
\hline Refused by patients & 17 (23\%) & & \\
\hline Done and failed & $12(16 \%)$ & & \\
\hline Not done as it was expected to fail & $45(61 \%)$ & & \\
\hline
\end{tabular}

if failed, they were treated by open CBD exploration and choledochoenterostomy. Those associated with multiple intrahepatic stones were treated in the same unit by Rouxen-Y hepaticojejunostomy and subcutaneous access loop.

Patient's choice, failure and expected failure of preoperative ERCP were the main indications for open choledochotomy for CBD stones in this study. Despite the great benefit of ERCP, it may cause severe complications, such as pancreatitis, perforation of the duodenum or bile duct, cholangitis, bleeding, and cardiac and pulmonary complications. ${ }^{39,40}$ Furthermore, if the gastric tract has been modified by an operation, it may be difficult to reach Vater's papilla endoscopically. Neoptolemos et al ${ }^{41}$ reported that endoscopic stone retrieval combined with endoscopic sphincterotomy (ES) has its place, but that it should be reserved for a specific group of patients. It is 
Table 2: Intraoperative parameters.

\begin{tabular}{|l|l|l|l|}
\hline Patients' data & Number = 74 & Median & Range \\
\hline Surgery & $65(88 \%)$ & & \\
$\quad$ Elective & $9(12 \%)$ & & \\
$\quad$ Emergency & $12.3+3.2$ & 11 & $8-27$ \\
CBD diameter (mm) & $3.4+1.4$ & 3 & $1-14$ \\
Number of CBD stones & $11+4.9$ & 10 & $5-32$ \\
Stones maximum diameter (mm) & $0 \%$ & & \\
Blood transfusion & $74(100 \%)$ & & \\
Successful duct clearance & $4.2+1$ & 4 & $3-7$ \\
Postoperative hospital stay (days) & & & \\
Complications & $3(4 \%)$ & & \\
$\quad$ Wound infection & $1(1.4 \%)$ & & \\
$\quad$ Bile leakage & $0 \%$ & & \\
Mortality & $10.8+3.2$ & 12 & $4-18$ \\
Follow-up & $73(98.6 \%)$ & & \\
$\quad$ Duration (months) & & \\
$\quad$ Patients who attended follow-up & $0 \%$ & & \\
$\quad$ Retained or recurrent CBD stones & $0 \%$ & & \\
$\quad$ CBD stricture & $0 \%$ & & \\
Hospital re-admission/re-operation & $0 \%$ & & \\
\hline
\end{tabular}

particularly beneficial in acute pancreatitis, severe cholangitis and residual stones and in patients with significant co-morbidities who are not fit for surgery.

Two surgical procedures -laparoscopic and open laparotomy to remove CBD stones- are performed worldwide. Laparoscopic CBD exploration with laparoscopic duct closure is technically challenging, very complicated and should be carried out by skilled laparoscopic surgeons. Furthermore, not all types of CBD stones are indicated for this procedure. The clearance rate was reported to be $75 \%-99 \% .{ }^{42-45}$ The recurrence rate after laparoscopic surgery was 3.2\%. ${ }^{15}$ Technical problems requiring repeated surgeries were also reported after LCBDE, and some of them were burden. ${ }^{11}$ The above factors make many doctors hesitant to choose the laparoscopic approach.

In this study, a longitudinal incision for choledochotomy was chosen because of its easiness with no risk of stenosis. ${ }^{46}$ Khaled et $\mathrm{al},{ }^{44}$ in their study, preferred transverse choledochotomy for CBD exploration. They found it easier and less likely to result in a duct stricture when the duct was slightly dilated. Decker et $\mathrm{al}^{47}$ performed LCBDE via transverse choledochotomy followed by primary duct closure in 100 cases and reported no biliary strictures postoperatively with a median follow-up of 28 months, whilst Cai et $\mathrm{al}^{48}$ reported no biliary strictures amongst 137 longitudinal choledochotomies with primary closure at a median follow-up of 26 months.

The presence of many stones was not a contraindication for primary closure. Thorough clearance of CBD stones and dirty bile was considered to be the most important, but not the number of stones. After total lithotomy, the choledochotomy line was closed primarily when smooth flow of the contrast medium to the duodenum was shown on cholangiography. Therefore, the function of Vater's papilla was assessed just from cholangiography. For this reason, preoperative US, transcystic IOC, and choledochoscopy were used to evaluate the number and size of stones in the CBD and to make sure that no calculus was retained before suture. Severe pancreatitis, cholangitis, and a CBD diameter of less than $8 \mathrm{~mm}$ were considered as contraindications for primary 
closure. However, severe pancreatitis and cholangitis were first treated conservatively, and then surgery could be done after the patient had reached a non-inflammatory state.

T-tube drainage of the CBD after open exploration has been the method of choice for many years. ${ }^{23,49,50}$ It is performed for post-operative decompression of the CBD if outflow obstruction occurs. The T-tube acts as a foreign body around which bile pigments and bile salts may precipitate, and the incidence of recurring stones would be greater in patients with choledochotomy followed by T-tube drainage. ${ }^{51}$ Significant bile leak following T-tube removal is said to occur in a high percentage of cases. ${ }^{52}$ Moreover, T-tube drainage is associated with increased bile infection and wound infection. The other reasons for considering the use of T-tube drainage after choledochotomy are to extract the retained stones through the T-tube tract and to make postoperative radiologic visualization of the CBD. $23,49,50,53$ But these objectives can also achieved with intra-operative choledochoscopy and post-operative ERCP. Intra-operative choledochoscopy can decrease residual stones to a large extent and make sure unobstructed CBD under direct observation during operation. If there are residual stones by any chance, the stones can be extracted by ERCP, and biliary drainage can recover similarly. ${ }^{54-56}$ Sawyers et al ${ }^{31}$ documented the advantages of primary closure of the CBD and recommended abandonment of the routine use of a T-tube following CBD exploration. T-tubes are not only expensive but are also associated with prolonged hospital stay and complications such as retained stones, retained T-tube fragments, inflammatory polyps, sepsis, premature dislodgement, biliary fistula, late biliary stricture, bile leakage and peritonitis. ${ }^{10,22,24,32,52,57-62}$ The use of the T-tube was considered appropriate only in cases of retained impacted stones that would require endoscopic extraction, serious cholangitis with frank pus in the CBD, or a very thin CBD. $45,47,63$

In Ambreen et $\mathrm{al}^{7}$ study, they found two cases of bile leakage in patients in whom the T-tube was used $(2 / 19 ; 10.5 \%)$, and one case among the 16 patients $(6.3 \%)$ in whom primary closure of the CBD was done. Yamazaki et $\mathrm{al}^{9}$ reported an incidence of $11.7 \%$ and $5.8 \%$ respectively. On the other hand, other authors reported no cases of bile leakage after primary closure. ${ }^{29,30}$

Primary closure of CBD following routine choledochotomy was a safe alternative to the insertion of a T-tube.7,20,21,23,64 Gurusamy et al ${ }^{65,66}$ performed two metaanalyses with regard to primary closure versus T-tube drainage after either open or laparoscopic common bile duct exploration in 2007 using data from six studies and one study, respectively, which reached a conclusion that primary closure after CBD exploration seemed at least as safe as T-tube drainage. But the number of patients included was small and the up-to-date studies were not included.

In fact, a '12-year follow-up' study found that the diameter of the dilated CBD returns to preoperative normal or near normal values in $75 \%$ of patients after surgical exploration of the CBD and extraction of the stones. ${ }^{67}$ Several studies had showed that residual stone rate was low (near 0\%) after primary closure because of the application of intraoperative choledochoscopy. $7,20,21$

Zhu et al68 in their meta-analysis demonstrated statistically significant difference for operating time and postoperative hospital stay and the total cost of treatment between primary closure and T-tube drainage groups after common bile duct exploration for choledocholithiasis. In the primary closure group, patients remained in the hospital for a shorter period and were not burdened by a T-tube. In patients where the T-tube has been kept in place, there was the additional cost of postoperative cholangiography. Their meta-analysis tended to favor primary closure over T-tube drainage in the prevention of the development of postoperative complications. In addition, it is unacceptable and uncomfortable for patients to go home with a functioning T-tube, and the risks of dehydration and saline depletion in such patients at home are contraindications to 
this technique. ${ }^{21}$ On the other hand, the old latex tube was very irritant and could safely be removed within a week or so. But the current siliconised T-tube requires $4-6$ weeks in situ to produce a reliable tract. This increases the morbidity and discomfort of T-tube drainage for the majority of patients. Wu et $\mathrm{al}^{69}$ in their meta-analysis indicates that primary closure of the common bile duct is safer and more effective than T-tube drainage for LCBDE. Therefore, they do not recommend routine performance of T-tube drainage in LCBDE.

Primary closure during emergency CBD exploration is furthermore controversial. ${ }^{45}$ In the present case series, $12 \%$ of the CBD exploration was done on emergency basis and still no T-tubes were inserted. Alhamdani et al ${ }^{45}$ performed primary closure of choledochotomy after emergency CBD exploration and reported its safety and feasibility.

No major complications and no deaths occurred in this study. Intraperitoneal leakage with subsequent biliary peritonitis have been reported.1,16,22 No such complication occurred in this study. The reason for this was probably that choledochoscopy and IOC were used to ensure complete duct clearance and the lower end of the CBD was not probed. This is beside delicate suturing of the CBD incision. These measures reduced the risk of biliary leakage. Interrupted sutures are recommended with absorbable material, which may reduce the recurrence of stones and stenosis of the CBD.

Bile leakage following primary closure is a major criterion for assessing the safety of this procedure. In this study, only one patient (1.4\%) suffered from bile leakage; this is comparable to the bile leak rates of $2-4.5 \%$ reported by others. $45,47,48$ The case of bile leak reported in this study may be from the duct of Luschka or from the choledochotomy site. However, the bile was completely drained by the non-suction catheter and its volume was decreasing and subsided on the third postoperative day.

There are many advantages of primary closure after CBD exploration, including early discharge from hospital, decreased post-operative complications, and no discomfort due to T-tube. Early discharge from hospital means an early return to work, which further has an indirect effect on the expenses of the patient. ${ }^{27}$ In a developing country like Egypt, this difference in expenditure has a major impact on public health. Many papers support the direct closure of the CBD immediately after exploration. 16,23,27,65,66

The fact remains that much of the equipment and training available to the developed world are still not available in the Third-World setting. Many surgeons in limited resource settings are very well experienced with the open techniques; hence open biliary surgery has its specific role to play in these settings. Interestingly, the confidence level of surgical residents in the modern 'laparoscopic' era are low due to minimal exposure to open techniques and are not able to perform better in critical situations requiring an open approach.

\section{Conclusion:}

Primary closure of the CBD after open choledochotomy is a safe, feasible and effective approach to the management of choledocholithiasis that offers a single-stage treatment, a low morbidity rate, a low cost, and a short postoperative hospital stay.

Primary closure can improve the quality of life and avoid the complications specifically associated with the use of a T-tube for biliary drainage.

The most important point for primary closure is to ensure that all CBD stones are retrieved, confirming their clearance by choledochoscopy and intraoperative cholangiography. Careful suturing of the choledochotomy site must be done to prevent bile leakage or stenosis.

\section{Reference}

1- Perez G, Escalona A, Jarufe N, et al: Prospective randomized study of T-tube versus biliary stent for common bile duct decompression after open choledochotomy. World J Surg 2005; 29: 869-872.

2- Hemli JM, Arnot RS, Ashworth JJ et al: Feasibility of laparoscopic common bile duct exploration in a rural centre. ANZJ Surg 
2004; 74: 979-982.

3- Hungness ES, Soper NJ: Management of common bile duct stones. J Gastrointest Surg 2006; 10: 612-619.

4- Ponsky JL, Heniford BT, Gersin K: Choledocholithiasis: Evolving intraoperative strategies. Am Surg 2000; 66: 262-268.

5- Freitas ML, Bell RL, Duffy AJ: Choledocholithiasis: Evolving standards for diagnosis and management. World $J$ Gastroenterol 2006; 12(20): 3162-3167.

6- Verbesey JE, Birkett DH: Common bile duct exploration for choledocholithiasis. Surg Clin N Am 2008; 88: 1315-1328.

7- Ambreen M, Shaikh AR, Jamal A, Qureshi JN, Dalwani AG, Memon MM: Primary closure versus T-tube drainage after open choledochotomy. Asian J Surg 2009; 32(1): 21-25.

8- Martin DJ, Vernon DR, Toouli J: Surgical versus endoscopic treatment of bile duct stones. Cochrane Database Syst Rev 2006; CD003327

9- Yamazaki M, Yasuda H, Tsukamoto S, et al: Primary closure of the common bile duct in open laparotomy for common bile duct stones. J Hepatobiliary Pancreat Surg 2006; 13: 398-402.

10- Sikic N, Tutek Z, Strikic N: Primary suture vs. T-tube after common bile duct exploration (our 25 years of experience). Przegl Lek 2000; 57: 143-145.

11- Martin IJ, Bailey IS, Rhodes M, et al: Towards T-tube free laparoscopic bile duct exploration. A methodologic evolution during 300 consecutive procedures. Ann Surg 1998; 228: 29-34.

12- Tokumura H, Umezawa A, Cao $\mathrm{H}$, et al. Laparoscopic management of common bile duct stones: transcystic approach and choledochotomy. J Hepatobiliary Pancreat Surg 2002; 9:206-212.

13- Lezoche E, Paganini AM, Carlei F, Feliciotti F, Lomanto D, Guerrieri M: Laparoscopic treatment of gallbladder and common bile duct stones: a prospective study. World $J$ Surg 1996; 20: 535-541.

14- Gigot FJ, Navez B, Etienne J, et al: A stratified intraoperative surgical strategy is mandatory during laparoscopic common bile duct exploration for common bile duct stones. Lessons and limits from an initial experience of 92 patients. Surg Endosc 1997; 11: 722-728.

15- Paganini AM, Lezoche E: Follow-up of
161 unselected consecutive patients treated laparoscopically for common bile duct stones. Surg Endosc 1998; 12: 23-29.

16- Tu Z, Li J, Xin H, et al: Primary choledochorrhaphy after common bile duct exploration. Dig Surg 1999; 16: 137-139.

17- Paganini AM, Guerrieri M, Sarnari J, et al: Long-term results after laparoscopic transverse choledochotomy for common bile duct stones. Surg Endosc 2005; 19: 705-709.

18- Naraynsingh V, Hariharan S, Ramdass MJ, Dan D, Shukla P, Maharaj R: Open common bile duct exploration without T-tube insertion-two decade experience from a limited resource setting in the Caribbean. Indian J Surg 2010; 72: 185-188.

19- Bingener J, Schwesinger WH: Management of common bile duct stones in a rural area of the United States: results of a survey. Surg Endosc 2006; 20: 577-579.

20- Zhang WJ, Xu GF, Wu GZ et al: Laparoscopic exploration of common bile duct with primary closure versus T-tube drainage: a randomized clinical trial. J Surg Res 2009; 157: 1-5.

21- Leida Z, Ping B, Shuguang W, Yu H: A randomized comparison of primary closure and T-tube drainage of the common bile duct after laparoscopic choledochotomy. Surg Endosc 2008; 22: 1595-1600.

22- Wills VL, Gibson K, Karihaloot C, Jorgensen JO: Complications of biliary T-tubes after choledochotomy. ANZ J Surg 2002; 72: 177-180.

23- Williams JAR, Treacy PJ, Sidey P, et al: Primary duct closure versus T-tube drainage following exploration of the common bile duct. ANZ J Surg 1994; 64: 823-826.

24- Gharaibeh KIA, Heiss HA: Biliary leakage following T-tube removal. Int Surg 2000; 85: 57-63.

25- Robinson G, Hollinshead J, Falk G, et al: Technique and results of laparoscopic choledochotomy for the management of bile duct calculi. ANZ J Surg 1995; 65:347-349.

26- Placer G: Bile leakage after removal of T-tube from the common bile duct. Br J Surg 1990; 77: 1075.

27- Seale AK, Ledet WP JR: Primary common bile duct closure. Arch Surg 1999; 134:22-24.

28- Mercado MA, Chan C, Orozco H, et al: Bile duct injuries related to misplacement of " $\mathrm{T}$ tubes”. Ann Hepatol 2006; 5: 44-48.

29- Chen SS, Chou FF: Choledochotomy for biliary lithiasis: Is routine T-tube drainage 
necessary? Acta Chir Scand 1990; 156: 387-390.

30- Sorenson VJ, Buck JR, Chung SK, et al: Primary bile duct closure following exploration: an effective alternative to routine biliary drainage. Am J Surg 1994; 60: 451-455.

31- Sawyers JL, Herrington JL, Edwards WH: Primary closure of the common bile duct. Am J Surg 1965; 109: 107

32- Haq A, Morris J, Goddard C, Mahmud S, Nassar AH: Delayed cholangitis resulting from a retained T-tube fragment encased within a stone: A rare complication. Surg Endosc 2002; 16: 714

33- Walrond ER: Bile duct surgery without tubes or stents. West Indian Med J 1982; 31: 34-37.

34- Boerma D, Schwartz MP: Gallstone disease. Management of common bile-duct stones and associated gallbladder stones: Surgical aspects. Best Pract Res Clin Gastroenterol 2006; 20: 1103-1116.

35- Marilee L Freitas, Robert L Bell, Andrew J Duffy: Choledocholithiasis: Evolving standards for diagnosis and management. World J Gastroenterol 2006; 12:3162-3167.

36- Ko C, Lee S: Epidemiology and natural history of common bile duct stones and prediction of disease. Gastrointest Endosc 2002; 56: 165-169.

37- Hassab HEM, El-Riwini MT, Sorour MA, El-Zeiny MM: Laparoscopic management of choledocholithiasis. Bull Alex Fac Med 2006; 42: 377-84.

38- Ghazal AH, Sorour MA, El-Riwini MT, ElBahrawy $\mathrm{H}$ : Single-step treatment of gall bladder and bile duct stones: A combined endoscopic-laparoscopic technique. Int $J$ Surg 2009; 7: 338-346.

39- Coppola R, Riccioni ME, Ciletti S, et al: Analysis of complications of endoscopic sphincterotomy for biliary stones in a consecutive series of 546 patients. Surg Endosc 1997; 11:129-132.

40- Pereira-Lima JC, Rynkowski CB, Rhoden EL: Endoscopic treatment of choledocholithiasis in the era of laparoscopic cholecystectomy: Prospective analysis of 386 patients. Hepatogastroenterology 2002; 48:1271-1274.

41- Neoptolemos JP, Carr-Locke DL, Fossard DP: Prospective randomised study of preoperative endoscopic sphincterotomy versus surgery alone for common bile duct stones. $\mathrm{Br}$ Med J (Clin Res Ed) 1987;
294(6570): 470-474.

42- Khoo DE, Walsh CJ, Cox MR, Murphy CA, Motson RW: Laparoscopic common duct exploration. Br J Surg 1996; 83: 341-346.

43- Berthou JC, Drouard F, Charbonneau P, Moussalier K: Evaluation of laparoscopic management of common bile duct stones in 220 patients. Surg Endosc 1998; 12: 16-22.

44- Khaled YS, Malde DJ, de Souza C, Kalia A, Ammori BJ: Laparoscopic bile duct exploration via choledochotomy followed by primary duct closure is feasible and safe for the treatment of choledocholithiasis. Surg Endosc 2013; 27: 4164-4170.

45- Alhamdani A, Mahmud S, Jameel M, Baker A: Primary closure of choledochotomy after emergency laparoscopic common bile duct exploration. Surg Endosc 2008; 22: 2190-2195.

46- Shimizu S, Yokohata K, Mizumoto K, Yamaguchi K, Chijiiwa K, Tanaka M: Laparoscopic choledochotomy for bile duct stones. J Hepatobiliary Pancreat Surg 2002; 9: 201-205.

47- Decker G, Borie F, Millat B, et al: One hundred laparoscopic choledochotomies with primary closure of the common bile duct. Surg Endosc 2003; 17(1): 12-18.

48- Cai H, Sun D, Sun Y, Bai J, Zhao H, Miao Y: Primary closure following laparoscopic common bile duct exploration combined with intraoperative cholangiography and choledochoscopy. World J Surg 2012; 36(1): 164-170.

49- De Roover D, Vanderveken M, Gerard Y: Choledochotomy: Primary closure versus T-tube. A prospective trial. Acta Chir Belg 1989; 89: 320-324.

50- Paganini AM, Feliciotti F, Guerrieri M et al: Laparoscopic common bile duct exploration. J Laparoendosc Adv Surg Tech A 2001; 11: 391-400.

51- Rienhoff WF: Primary closure of the common duct. Ann Surg 1960; 151: 255-260.

52- Moreaux J: Traditional surgical management of common bile duct stones: a prospective study during a 20-year experience. Am J Surg 1995; 169: 220-226.

53- Burhenne HJ: Non-operative retained biliary tract stone extraction. Calif Med 1972; 117: 57.

54- Berci G, Shore M, Morgenstern L, Hamlin A: Choledochoscopy and operative fluorocholangiography in the prevention of retained bile duct stones. World J Surg 1978; 
2: 411-427.

55- Cotton PB: Non-operative removal of bile duct stones by duodenoscopic sphincterotomy. Br J Surg 1980; 67: 1-5.

56- Hauer-Jensen M, Karesen R, Nygaard K et al: Predictive ability of choledocholithiasis indicators. A prospective evaluation. Ann Surg 1985; 202: 64-48.

57- Lygidakis NJ: Choledochotomy for biliary lithiasis: T-tube drainage or primary closure. Effects on postoperative bacteremia and T-tube bile infection. Am J Surg 1983; 146: 254-256.

58- Bernstein DE, Goldberg RI, Unger SW: Common bile duct obstruction following T-tube placement at laparoscopic cholecystectomy. Gastrointest Endosc 1994; 40: 362-365.

59- Hotta T, Kaniguchi K, Kobayashi Y, et al: Biliary drainage tube evaluation after common bile duct exploration for choledocholithiasis. Hepatogastroenterology 2003; 50: 315-321.

60- Pappas TN, Slimane TB, Brooks DC: 100 consecutive common bile duct explorations without mortality. Ann Surg 1990; 211: 260-262.

61- Watanabe H, Iwase $H$, Sugitani M: Inflammatory polyps in common bile duct caused by T-tube. Hepatogastroenterology 2002; 49: 894-896.

62- Marwah S, Singh I, Godara R et al: Evaluation of primary duct closure vs T-tube drainage following choledochotomy. Indian J Gastroenterol 2004; 23: 227-228.
63- Krauss H, Kern E: Some current problems of biliary tract surgery: Indications and technique of choledochotomy, intraoperative cholangiomanometry, primary closure of the common bile duct. Surgery 1967; 62: 983-987.

64- Payne RA, Woods WG: Primary suture or T-tube drainage after choledochotomy. Ann R Coll Surg Engl 1986; 68: 196-198.

65- Gurusamy KS, Samraj K: Primary closure versus T-tube drainage after laparoscopic common bile duct stone exploration. Cochrane Database Syst Rev 2007; CD005641.

66- Gurusamy KS, Samraj K: Primary closure versus T-tube drainage after open common bile duct exploration. Cochrane Database Syst Rev 2007; CD005640.

67- Csendes A, Csendes P, Burdiles P, Diaz JC, Maluenda F, Burgos AM: Behavior of the common bile duct diameter before and 12 years after choledochostomy for cholecystolithiasis and choledocholithiasis. A prospective study. J Gastrointest Surg 2007; 11: 1294-1297.

68- Zhu QD, Tao CL, Zhou MT, Yu ZP, Shi HQ, Zhang QY: Primary closure versus T-tube drainage after common bile duct exploration for choledocholithiasis. Langenbecks Arch Surg 2011; 396: 53-62.

69- Wu X, Yang Y, Dong P, et al: Primary closure versus T-tube drainage in laparoscopic common bile duct exploration: A metaanalysis of randomized clinical trials. Langenbecks Arch Surg 2012; 397: 909-916. 